\title{
Multidisciplinary audit in child and adolescent psychiatry
}

\author{
ANDRew Leahy, Senior Registrar; M. S. Thambirajah, Senior Registrar; and \\ Linda M. WinkLeY, Consultant, Department of Child and Adolescent Psychiatry, \\ Oaklands Centre, Selly Oak Hospital, Selly Oak, Birmingham B29 6JB
}

Recent guidelines recommend that where appropriate, procedures for the development of audit in medicine and professions allied to medicine can be replaced by comprehensive multidisciplinary audit of services. The Royal College of Psychiatrists (1990) suggests that clinical audit, involving the work of other staff in the multidisciplinary team, is preferable to purely medical audit. Given the importance of team work in child psychiatry, it seems appropriate to establish a system of audit which enables all disciplines to be involved.

The potential advantages of this approach are considerable (Pearce, 1990). They include an acknowledgement of the work of all the team members, an improvement in the understanding of the contributions of different disciplines, and the development of a greater sense of cohesion in the team as a whole.

In addition to ensuring a high level of patient care, many professional bodies have emphasised the value of audit in training junior staff and its educational potential. We found that it was possible for both aspects to be fulfilled using a random review of patient records.

As our main aims were to observe and evaluate current practice, we found it useful to follow the three main principles developed by Yorkshire (Audit in Yorkshire, 1990): audit is locally based, part of everyday clinical practice; audit is a pragmatic examination of whether best practice is being achieved, rather than research into what best practice ought to be; and audit should be clinically led but should inform the management of services.

\section{The setting}

This is a child and adolescent psychiatry service in an urban area serving a population of 250,000 . The team consists of psychiatrists, community psychiatric nurses, social workers, child psychotherapists and an occupational therapist. The core members of the team have well established relationships and cross-disciplinary supervision of case work is a feature of the clinic's practice.

\section{The form}

The form takes into account the different approaches used in child psychiatry and is set out here.

\section{MULTIDISCIPLINARY AUDIT}

Date of audit:

Age:

Worker/s:

Time on waiting list:

Referral source:

Problems described by:

(1) Identified patient:

(2) Parents/carer:

(3) Referrer:

(4) Other agencies:

Number of people taken as patients:

Other worker/s involved and in what way:

Assets of:

(1) Patient

(2) Family

Degree of difficulty of the case:

(1) Child's problem: Easy .... moderate .... difficult.

(2) Parents' problem: Easy.... moderate .... difficult.

Initial assessment:

Predicted outcome at assessment:

\section{MANAGEMENT PLAN}

Aims of treatment:

Was a problem list created?

Was a treatment plan created?

Did treatment plan require additional resources?

Were plans discussed with a senior member of staff?

Did the treatment plan require modifications?

\section{OUTCOME}

Were aims of treatment fulfilled?

Were items in the plan carried through?

If not, why?

Treatment outcome as rated by the worker:

(1) Symptom reduction:

(2) Generalisation of improvement:

(3) Promotion of development and maturation:

(4) Fostering of autonomy and self-reliance:

(5) Environmental changes:

(a) in family

(b) in school

(c) in community 
Treatment outcome from identified patient's point of view.

Was outcome predicted?

\section{OVERVIEW}

What went well with the case?

What went badly with the case?

Were there any unmet needs?

What could have been done differently?

Number of times seen:

Method of termination of contact:

Any other observations:

\section{DOCUMENTATION}

Are the notes coherent?

Letter to GP/referrer:

Initial assessment form:

Six monthly summary:

School report:

Discharge summary:

The intention is to ensure a clear delineation of the problems, the methods used to deal with these and the outcome (Rutter, 1982). Two sets of notes chosen randomly are audited by a team member and presented at the monthly audit meeting.

\section{An audited case, seen by the senior registrar}

Jane, a 14-year-old girl living with her single parent mother, was seen following an overdose of haloperidol. Her mother suffered from manic depressive psychosis and had had ten admissions to hospital, usually on a Section. She had been violent towards Jane and on occasions had tried to strangle her. The assessment was that Jane had no formal psychiatric disorder but was reacting to a very stressful situation.

The senior registrar and consultant agreed that the aims were to reduce suicide risk and stabilise Jane's development and that these could be achieved by encouraging her to live with her sister. Having liaised with the GP, the mother's psychiatrist and the unit social worker, the senior registrar then explored the possibility of formalising the sisters' relationship through a Guardianship Order at their first outpatient visit. However, neither were interested but the sister had now made definite provision for Jane. At the second visit Jane reported that she was now living with her sister and was much happier. She failed further appointments. However, when contacted by telephone she said that she felt settled and was visiting her mother twice a week.

It was felt at the audit meeting that the aims of treatment had been achieved, mainly through environmental manipulation. The sisters seemed threatened by the mention of Guardianship and this could have been left until later. There was felt to be generalisation of improvement as Jane was doing well at school as well as potential for promotion of development. Jane had established a stable relationship with her sister and it was hoped this would enable her to acquire the ability to cope with future problems. Documentation was complete.

\section{Comment}

This method of audit has not proved to be particularly threatening. It has shown that patients clearly benefited from the particular skills of the allocated worker. One unforeseen advantage was the effect on morale within the team. The sharing of cases in which some change had been possible increased our own hopefulness and awareness of what can be achieved. Finally, this system of audit has led to more clearly defined policies on actual recording so that we now have an initial assessment form, a contact sheet, a six monthly summary, and a discharge form.

\section{Conclusion}

The form and its current usage are clearly only one part of an overall clinic audit. However, our experience so far provides evidence for the educational value of multidisciplinary audit and for the role of reflection in improving clinical practice.

\section{Acknowledgement}

We are very grateful to the members of staff who allowed us to describe their case.

\section{References}

AUdit IN YORKSHIRE (1990) British Medical Journal, 301, 533.

Pearce, J. (1990) Taking a Lead in Audit. Child and Adolescent Psychiatry: Into the 1990s. London: Royal College of Psychiatrists, Occasional Paper 8, 64.

Royal College of Psychiatrists (1990) College guidance on consultant contracts and job plans. Psychiatric Bulletin, 14, 591.

RUTTER, M. (1982) Psychological therapies in child psychiatry: issues and prospects. Psychological Medicine, 12, 723-740. 